\title{
EFFECTIVENESS OF PHYSICAL THERAPY IN MYOFASCIAL SYNDROME IN PATIENTS WITH MULTIPLE SCLEROSIS
}

DOI: 10.36740/WLek202009210

\author{
Zinovyi M. Ostapyak', Bogdan M. Mytckan', Przemyslaw Bejga², Roman P. Gerich', Serg L. Popel'1 \\ 'VASYL STEFANYK PRECARPATHIAN NATIONAL UNIVERSITY, IVANO-FRANKIVSK, UKRAINE \\ ¿UNIVERSITY OF ZIELONA GÓRA, ZIELONA GÓRA, POLAND
}

\begin{abstract}
The aim: Is to conduct a comparative analysis of electroneuromyographic parameters in patients with myofascial pain syndrome with multiple sclerosis under the conditions of using various means of physical therapy.

Materials and methods: 105 patients aged 21 to 54 years were examined with MPS in MS. Neurological disorders were verified according to ENMG examinations. 64 patients were enrolled in an experimental group for which a specially designed program was included, which included reflexology and exercise for stretching muscles for 30 days. The control group included 41 patients who underwent a FT course based on therapeutic massage during the same time. Analysis of global ENMG was performed according to functional tests («muscle relaxation» and «maximum arbitrary muscle tension» with $\mathrm{m}$. Tibialis anterior and $\mathrm{m}$. Rectus femoris), M-responses and H-reflexes, polysynaptic responses (PSV) in withdrawal from these muscles during short-term stimulation n. plantaris (number of pulses in series 10 , frequency - $20 \mathrm{~Hz}$, duration of a separate stimulation signal - 1 ms, intensity - double threshold of contractile response of the muscles of the sole of the foot) and residual latency as the time of motor impulse on terminal non-myelinated nerve. Testing was performed on the same muscle groups on the left and righ.

Results: Before physical therapy during electromyographic testing, a significant decrease in the amplitude of the maximum M response, a decrease in the speed of the impulse in the proximal and distal segments of the peripheral nerve, was found to be significant compared with the control, the ratio of the proximal-distal coefficient and the residual latency index significantly increased, which indicates a demyelinating character lesions of nerve conductors. After reflexotherapy with muscle stretching in $38.0 \%$ of the patients of the experimental group, the dynamics of the amplitude of the M-answers on the left and on the right has only a tendency to further increase, while in the other $62.0 \%$ of patients, the amplitude of the M-responses increases bilaterally and is $65.7 \%$ higher than in the control group.

Conclusions: The use of reflexology in conjunction with stretching leads to a reduction in muscle spasticity and pain, as evidenced by electrophysiological indicators that substantiate their feasibility in the practice of physical therapy to improve the functional status of patients with MPS in MS.
\end{abstract}

KEY WORDS: multiple sclerosis, myofascial pain syndrome, electroneuromyographic, reflexology, stretching

Wiad Lek. 2020;73(9 p. II):1950-1956

\section{INTRODUCTION}

To date, multiple sclerosis (MS) remains a severe disease with wavy currents, periods of exacerbation, and partial remission $[1,2]$. Its medico-social importance is determined primarily by the development of early and persistent disability [3,4]. Numerous studies have found that within the first five years from the onset of MS, half of patients lose their ability to work, and when the disease lasts up to 10 years, their number is almost $2 / 3$ of all patients with this diagnosis $[5,6,7]$. Despite the existence of a large number of publications, there are many problems in the etiopathogenetic theory of myofascial pain syndrome (MPS) in MS, without which further progress in the diagnosis and treatment of this disease is impossible $[8,9,10]$. The "white spots" about the causes of MPS in MS were highlighted, and it allowed us to show directions for further research, the results of which allow us to optimize existing diagnostic and therapeutic methods, especially for the development of modern pathogenetically substantiated physical therapy regimens and programs [11].
In recent years, the prevalence of MPS in MS throughout the world has significantly increased $[12,13]$. This is due both to a true increase in the incidence rate of MS, and to an improvement in diagnostic methods with the widespread introduction of modern neuroimaging methods of research into neurological practice that can detect diseases in the early stages of development $[14,15,16]$.

The accumulated knowledge about the pathogenesis of MPS in MS in recent years may lead to the development of effective methods of prevention and treatment in the near future. $[17,18]$.

Existing methods of treatment allow, with varying degrees of effectiveness, to reduce the risk of exacerbations, slow down the progression of the disease, and delay disability $[19,20]$. Despite some progress, the problem of treatment of MPS in MS requires further detailed study. In this case, it is necessary to conduct large-scale randomized trials of new drugs, check and confirm the results of experimental clinical studies [21,22], which is associated with 
Table I. Electroneuromyographic parameters of patients before and after the introduction of a physical therapy program compared with the control group $(\mathrm{x} \pm \mathrm{SE})$

\begin{tabular}{ccccc}
\hline \multirow{2}{*}{ Parameter } & \multicolumn{2}{c}{ Before } & \multicolumn{2}{c}{ After } \\
\cline { 2 - 5 } & EG & CG & EG & CG \\
\hline Amplitude of the M response, $\mu \mathrm{V}$ & $6,75 \pm 0,23$ & $6,73 \pm 0,31$ & $8,31 \pm 1,01^{* \otimes}$ & $7,02 \pm 0,76$ \\
\hline Slprox., $\mathrm{m} / \mathrm{s}$ & $49,21 \pm 1,05$ & $49,11 \pm 1,05$ & $65,72 \pm 1,88^{* \otimes}$ & $53,07 \pm 1,43$ \\
\hline Sldist., $\mathrm{m} / \mathrm{s}$ & $39,24 \pm 0,62$ & $39,25 \pm 0,59$ & $61,02 \pm 1,74^{* \otimes}$ & $49,59 \pm 1,47^{*}$ \\
\hline Proximal-distal coefficient & $0,88 \pm 0,04$ & $0,87 \pm 0,03$ & $1,27 \pm 0,03^{* \otimes}$ & $1,12 \pm 0,02^{*}$ \\
\hline Residual latency, ms & $3,09 \pm 0,151$ & $3,07 \pm 0,11$ & $1,66 \pm 0,04^{* \otimes}$ & $2,08 \pm 0,04^{*}$ \\
\hline
\end{tabular}

Notes: ${ }^{*}$ significant difference compared with indicators before starting physical therapy at $p<0.05$; $\nabla$ a significant difference compared with the control group at $p<0,05$.

the expenditure of large financial and human resources. Therefore, physical therapy (FT) is gaining importance, which has few contraindications and possible complications $[17,18]$. The most common means of FT are exercise and various physical factors [23].

The use of physical exercises for the symptoms associated with pain in the lower back and lower extremities in MS is determined by practical requests for a theoretical justification for their use in order to correct the functional state of the neuromuscular system in this category of patients.

In the specialized literature [8], only a few works relate to the estimation of the amplitude-frequency characteristics of the reflex excitability of spinal motor neurons in MPS in combination with MS. However, this is very important, because simple reflexes along a monosynaptic reflex arc that affect the manifestation of voluntary motor activity are realized through them. Therefore, the data of electroneuromyographic (ENMG) studies on the effect of FT contribute to a deeper and more comprehensive understanding of the mechanisms for organizing responses at the spinal and peripheral motor levels. At the same time, multisynaptic testing allows us to assess the level of reflex excitability of muscles to which the appropriate FT methods are used in patients with MPS in MS.

\section{THE AIM}

The aim of the article is to conduct a comparative analysis of electroneuromyographic parameters in patients with myofascial pain syndrome with multiple sclerosis under the conditions of using various means of physical therapy.

\section{MATERIALS AND METHODS}

105 patients aged 21 to 54 years, who were admitted to the neurological department with the diagnosis of IFS in MS were examined. In all examined patients, at admission clinically diagnosed neurological disorders (lower mixed-type paraparesis) of varying severity, which were verified according to the ENMG-survey using global and stimulating methods.

Of these, 64 patients comprised an experimental group (EG) for which a specially designed program was used, which included reflexology and physical exercises to stretch muscles for 30 days.

The control group (CG) included 41 patients with MFBS in MS who underwent a course of FT, which is based on therapeutic massage for the same time [9].

The electromyographic (EMG) study was performed on a 2-channel computer Neuro-EMG-Micro (NEURO-SOFT, Russia). The complex of methods included registration and analysis of the global (total) ENMG (functional tests: "muscle relaxation" and "maximum voluntary muscle tension" with $\mathrm{m}$. Tibialis anterior and $\mathrm{m}$. Rectus femoris), $\mathrm{M}$-responses and $\mathrm{H}$-reflexes, polysynaptic responses (PSV) during abduction from these muscles with short-term stimulation n. plantaris (the number of pulses in a series of 10 , the frequency is $20 \mathrm{~Hz}$, the duration of a single stimulation signal is $1 \mathrm{~ms}$, the intensity is the double threshold of the contractile response of the muscles of the plantar surface of the foot) and residual latency as the time of the motor pulse along the terminal non-myelinated nerve fibers. Testing was carried out on the same muscle groups on the left and right.

The examinations were conducted directly upon admission to the neurological department and after 20 and 30 sessions after the start of the FT program.

Patients underwent appropriate clinical and neurological examination and specific manual-therapeutic diagnostics [8]. The severity of pain was determined on a visual-analogue scale (VAS) and the scale of life disorders Kurtzke (EDSS), and the degree of severity of chronic pain and its impact on social maladaptation was evaluated by Van Korf's questionnaire [9].

Statistical data processing was carried out using the Microsoft EXEL-2003 data package, supplemented with non-parametric statistics and distribution normality estimation statistics "Statistika-6".

\section{RESULTS}

Clinical studies have established that in $95.0 \%$ of patients with MBS in MS, the severity of pain according to YOUR is $6.0 \pm 0.03$ points, and according to EDSS - $4.0 \pm 0.02$ points. At the same time, the intensity of pain and the degree of social maladaptation according to the Van Corf questionnaire are 65 and 67 points, respectively, which refers to the second class of chronic pain. 




Fig. 1. Characterization of the potential of motor units in patients of the control group after the course of physical therapy according to the program of therapeutic massage.

When analyzing the results of stimulating ENMG, probable changes in the electrophysiological parameters characterizing the condition of the peripheral nerve conductors of the lower limb appear and are presented as average values in the table. 1. Survey data before FT indicate the presence of some features in the neurophysiological status of the sensorimotor innervation of the lower extremities in all patients with MS.

During ENMG testing, a significant decrease in the maximum amplitude of the M-response, a decrease in the speed of the impulse (SI) in the proximal and distal segments of the peripheral nerve, was found to be significant compared with the control, the ratio of the proximal-distal coefficient and the residual latency index significantly increased, which testified to the demyelinating nature of nerve damage conductors (see table I).

In particular, the average amplitude of the total EMG (test - "maximum arbitrary voltage") in individual leads was significantly lower than the reference values (on average by $43.2 \%, p<0.05$ ). For example, the average amplitude of the total EMG m. rectus femoris of the right and left lower extremities was $6.85 \mu \mathrm{V}$ and $6.64 \mu \mathrm{V}$, respectively $(61.0 \%$ and $83.0 \%$ of the reference values), the value of $\mathrm{m}$. tibialis anterior left and right lower extremities were $6.79 \mu \mathrm{V}$ and $6.66 \mu \mathrm{V}$ (44.5\% and $55.0 \%$ of the reference values).

After the introduction of the FT program with the use of reflexology in combination with muscle stretching, a bilateral increase in the amplitude of the total ENMG by an average of $23.4 \%$ of the values was noted, prior to FT.

Compared with the examination data before FT in patients with CG in whom only therapeutic massage was performed, a statistically unreliable bilateral increase in the amplitude of the total ENMG was noted.

In EG patients with whom acupuncture was performed without muscle tension, the N-reflex on the left was $3.4 \mu \mathrm{V}$ 




Fig. 2. Characterization of the potential of motor units in patients of the experimental group after the course of physical therapy.

(47.0\% of the control values) and the duration of the evoked potentials on the left was $3.1 \mathrm{mV}$ and $3.0 \mu \mathrm{V}$ on the right were slightly lower than the control values (respectively $12,0 \%$ i $15,0 \%)$.

In this case, compared to the values up to FT, the amplitude of the H-reflex in the drainage from $m$ is statistically significant $(\mathrm{p}<0.05)$, tibialis anterior increased by an average of $14.2 \%$, indicating a demyelinating nature of nerve fiber damage [20,24].

The exception was patients with CG, in whom, after FT using only therapeutic massage, a mono- or bilateral decrease in the amplitude of the H-reflex was noted by $47.8 \%$ and $42.0 \%$, respectively $(\mathrm{p}<0.05)$. Moreover, in all patients with CG in most leads, a decrease in the amplitude of $\mathrm{M}$ responses to an average of $82.7 \%$ of the magnitude before FT was noted, especially clearly reflected in the dynamics of the corresponding indicator in the lead from $m$. tibialis anterior.
In particular, the amplitude of the total ENMG allocated to $\mathrm{m}$. tibialis anterior on the left decreased from $6.7 \mathrm{mV}$ to $0.6 \mathrm{mV}$, which amounted to $90.0 \%$ of the values to the FT value, while latency increased from $25.6 \mathrm{~ms}$ to $40.3 \mathrm{~ms}$ (157.4\% of the value to FT).

In all patients with MS before FT, the amplitude of the total ENMH of the left and right limbs during the period was $3.1 \mathrm{mV}$ and $3.0 \mathrm{mV}$, respectively, and after FT decreased to $0.2 \mathrm{mV}$ and $0.3 \mathrm{mV}(6.5 \%$ and $10.0 \%)$, while latency increased from $26 \mathrm{~ms}$ and $23 \mathrm{~ms}$ to $41 \mathrm{~ms}$ and $40 \mathrm{~ms}(157.7 \%$ and $173.9 \%$ of the reference values, respectively).

A quantitative analysis of the main fluctuations of the global ENMG revealed in most cases (90.0\%) a clear asymmetry in the amplitude characteristic.

It should be noted that in $45.0 \%$ of patients with a high total score on the EDSS scale (6.5), the asymmetry of the 
amplitudes of the total ENMG (maximum 80.0\%) was also maximum for two muscle groups.

At the end of FT using acupuncture with muscle stretching in $38.0 \%$ of patients with EG in the lead from $\mathrm{m}$. tibialis anterior dynamics of the amplitude of $\mathrm{M}$-responses on the left and on the right has only a tendency to further increase, while in the other $62.0 \%$ of patients, the amplitude of the $\mathrm{M}$-response is $\mathrm{m}$. tibialis anterior bilaterally increased on average to $70.4 \%$ of the value that was observed upon admission to the hospital and was $65.7 \%$ higher than in the CG.

The knowledge of the interference pattern distinguished different potentials of motor units (PMU). In patients with CG, deviations from reference PMU duration were significantly $(\mathrm{p}<0.01)$ greater. Moreover, the duration of $\mathrm{PMU}$ is less than in patients with EG $(-3.62 \pm 0.14 \mathrm{i}-4.15$ \pm 0.17 , respectively) (Fig. 1 ).

At the same time, the deviation of the amplitude PMU in the EG is significantly $(\mathrm{p}<0.001)$ less than in the patients with CG $(+295.1 \pm 1.23$ and $+132.2 \pm 0.84$ respectively $)$ (Fig. 2).

\section{DISCUSSION}

After analyzing the data of scientific sources $[8,21]$ and studying the topographic and anatomical details of various parts of the spine in patients with MS [25,26], it can be argued that the cause of pain in lumbar localization is compensatory overstrain of the myofascial system, as a response to inadequate nerve impulses, which is a result of demyelination, and in some cases also axonopathies [6], which are confirmed by ENMG indicators.

The presence of subclinical variants of peripheral nervous system lesions, manifested only by ENMG methods, is shown, which must be taken into account when conducting FT $[10,27]$.

After a 20 -day course of FT, $70.0 \%$ of EG patients had positive clinical dynamics. Mild pain syndrome remained in only $30.0 \%$ of patients. In this case, pain appears only with a sharp transition from one body position to another, but was completely absent in a calm lying position and with moderate movements or a short stay on legs.

The method we used was especially effective for acute pain in the early days of FT. In the future, the integrated use of reflexology and muscle tension in the EG allowed: to reduce pain to minimum levels after 10 sessions; to restore indicators that affect the improvement of vital activity in Kurtzka after 20 sessions, which made it possible to more effectively reduce the severity of chronic pain and its effect on social maladaptation in the same period.

Moreover, already from the 20th session, a stably low level of spasticity $\mathrm{m}$ was established. tibialis ant. and $\mathrm{m}$. rectus femoris, and in the CG, a decrease in the level of tonic tension of these muscles was achieved only after a 30-day session of therapeutic massage according to the traditional treatment regimen for MS.

Assessment of electrophysiological and psychometric disorders in patients with MPS in MS showed that, prior to FT, an increase in the average amplitude and a decrease in the average duration of missile defense may correspond, firstly, to an increase in the excitation of $\alpha$-motor neurons, which is associated with a decrease in inhibitory effects on spinal motor neurons and interneurons in combination defeat of the pyramidal and extrapyramidal paths. In a different way, everything can be connected with the structure of the segmental apparatus of the spinal cord and skeletal organs, which is connected with the trivial nature of the disease. For the sake of processing, we need to bring them to the structurally functional functions of the fibers. In its entirety, the biomechanical component of spasticity and the regular manifestation in psychometric indicators show that the intensity of the pain syndrome and the level of social disadaptation.

Myofacial triggering points and refining in general, hereby created and massive proprioceptive afferents in the segmental structure of the central nervous system.

The above facts regarding the reduction of latency and stabilization of the duration of the H-reflex testify to the shortening of the path of its realization with the closure at the level of the caudal department of the brain stem on the side of the predominance of MPS. As the role of the communicative capacity of brainstem interneurons increased, the duration of the M-response was to increase. The reflection of the increased excitability of brainstem interneurons is a decrease in the threshold and latency period, an increase in the amplitude of the ENMG indicators.

The results obtained objectively characterize the failure of the inhibitory mechanisms in the central nervous system and the functional deficiency of the antinociceptive system in MS. The weakness of the inhibitory processes leads to the facilitation of sensory inputs for streams of peripheral afferentation and leads to the formation of generators of pathologically enhanced excitation in the efferent systems of the brain [2].

Our neuronal activity reflects the interaction of nociceptive and antinociceptive systems that are implemented by brain stem structures.

In patients with predominance of pain due to the involvement of muscles of one half of the body and the predominant involvement of the lower extremity, an increase in the maximum amplitude and area of the H-reflex, the $\mathrm{H} / \mathrm{M}$ index, the increase of the H-reflex was noted. Increase in amplitude of H-reflex [3], increase of $\mathrm{H} / \mathrm{M}[12,23]$ indicate a decrease in supraspinal impact, since in this case the excitability of the motor neuron pool increases and their synchronization increases. H-reflex amplification is not only dependent on the activity of spinal nociceptive neurons, but is also associated with the activation of supraspinal centers involved in the perception and analysis of "pain" signals and coordinating reflex muscle response in MS [2].

Thus, when MPS is strengthened, both due to the involvement of the half-body muscles and the predominant involvement of the muscles of the lower extremity, the level of segmental excitability of the spinal cord is increased. Direct correlation relationships of lower body MPS severity 
with $\mathrm{H}$-reflex rates reflect activation of spinal motoneurons. The direct correlation between the severity of myofascial half-body pain with the predominant involvement of the lower extremity muscles and the H-reflex indexes also indicate the activation of the supraspinal nociceptive centers.

\section{CONCLUSIONS}

1. The use of reflexology in combination with stretching is a highly effective effect on the number of positive results in reducing muscle spasticity ( $47.0 \%$ of the total number of patients), reducing the severity of pain (64.5\% of patients) and reducing the degree of exposure to chronic pain. to the level of social maladaptation (in $60.3 \%$ of patients with MPS in MS).

2. The results of the study, focused on the evaluation of electrophysiological characteristics of severity and dynamics of the development of myofascial pain syndrome and neurological deficiency due to multiple sclerosis, indicate the feasibility of monitoring the function of the root-segmental structures and corticospinal tracts.

3. Our proposed version of the specialized package of electromyromyographic techniques is easy to implement and is sufficiently high reproducible and informative of selected indicators.

4. The results obtained provide a justification for putting into practice physical therapy daily (within 30 days) acupuncture stimulation of the lower extremity muscle anti-gravity group while simultaneously stretching them as an adequate method of improving the functional status of patients with MPS in MS.

\section{REFERENCES}

1. Barkova E.N., Shmurigina E.A., Kurlovich N.A. Immunologicheskie narushenija pri rassejannom skleroze [Immunological shifts in multiple sclerosis in remission]. Collection of scientific theses and articles «Health and Education in the 21st Century». 2010; 2: 160.(in Russian).

2. Boyko A.N. Patogeneticheskoe lechenie rassejannogo skleroza: nastojashhee i budushhee [Pathogenetic treatment of multiple sclerosis: present and future]. Journal of Neurology and Psychiatry SS Korsakov. 2009; 109: 90-100. (in Russian).

3. Gusev E.I., Boyko A.N. Rasseyannyj skleroz: dostizheniya desyatiletiya [Multiple sclerosis: achievements of the decade]. Journal of Neurology and Psychiatry SS. Korsakova. 2007; 4: 4-14. (in Russian).

4. Karnauh B.H. Analiz invalidnosti pri rasseyannom skleroze [Analysis of disability in multiple sclerosis]. Siberian Medical Journal. 2011; 1: 115-117. (in Russian).

5. Boyko A.N. Soblyudenie bazovoj terapii u bolnyh rasseyannym sklerozom $s$ depressiej [Adherence to basic therapy in patients with multiple sclerosis with depression]. Neurological journal. 2011; 5: 41-45. (in Russian).

6. Guseva MR. Rasseyannyj skleroz i ego proyavlenie u lyudej raznogo vozrasta [Multiple sclerosis and its manifestation in people of different ages]. Russian pediatric ophthalmology. 2014;2:51-59. (in Russian).

7. Yevtushenko S.K. Sovremennye podhody k lecheniyu rasseyannogo skleroza: dostizheniya, razocharovaniya, nadezhdy [Modern approaches to the treatment of multiple sclerosis: achievements, disappointments, hopes]. International Neurological Journal. 2006; 6 (2): 23-28. (in Russian).
8. Vasil'yeva L.F.Klinicheskaya ivizualnaya diagnostika kontraktury [Clinic and visual diagnosis of shortened muscles] M:Medicine. 2003:169. (in Russian).

9. Essin W.G. Miogennyj bolevoj sindrom. Bol: principy terapii, bol v manualnoj medicine [Myogenic pain syndrome. Pain: Principles of therapy, pain in manual medicine]. Kazan: Offset Company. 2008: 131. (in Russian)

10. Tardov M.V. Miofascialnyj sindrom: proishozhdenie, proyavleniya, principy lecheniya. Trudnyj pacient. [Myofascial syndrome: origin, manifestations, principles of treatment. Difficult patient]. A journal for doctors. 2014; 11:1-10. (in Russian).

11. Maltsev D.V. Rasseyannyj skleroz: Nereshennye problemy i perspektivy issledovaniya [Multiple sclerosis: a solution to the problem and prospects for research]. Ukrainian neurological journal. 2013; 27 (2): 8-16. (in Russian).

12. Makarov A.I. Dobrokachestvennyj rasseyannyj skleroz, ocenka deesposobnosti bolnyh [Benign multiple sclerosis, assessment of the ability of patient] Practical medicine. 2013;68 (1):114-116. (in Russian).

13. A new era in the study of multiple sclerosis: views on therapeutic approaches. Sweet Group Press, 2012: 94.

14. Kicherov 0.A. Rasseyannyj skleroz [Multiple sclerosis]. Tyumen: City Press, 2017: 256 .(in Russian).

15. Panteleeva E.A. Spasticheskij parez pri rasseyannom skleroze: klinicheskie, nejrofiziologicheskie i biohimicheskie aspekty [Spastic paresis in multiple sclerosis: clinical, neurophysiological and biochemical aspects]. Neurological journal. 2009; 5: 18-21. (in Russian).

16. Hamidulla A.A. Sovremennye aspekty diagnostiki i lecheniya rasseyannogo skleroza [Modern aspects of the diagnosis and treatment of multiple sclerosis]. Neurosurgery and neurology of Kazakhstan. 2016; 42 (1):24-30. (in Russian).

17. Schmidt T.E. Towards an Individualized Approach to the Treatment of Multiple Sclerosis Patients/ Neurological Journal. 2011; 16(2): 4-10.

18. Schmidt T.E. Pathogenetic treatment of multiple sclerosis. Medical Council. 2010; 9-10: 74-79.

19. Chun J. Mechanism of action of oral fingolimod (FTY720) in multiple sclerosis. Clin Neuropharmacol. 2010; 33: 91-101.

20. Dhib-Jalbut $S$. Pathogenesis of myelin/oligodendrocyte damage in multiple sclerosis. J. Neurology. 2007; 68(3): 13-21.

21. Hutchinson M. The efflcacy of natalizumab in patients with relapsing multiple sclerosis: subgroup analyses of AFFIRM and SENTINEL. J. Neurol. 2009;256:405-415.

22. Pittock S.J. Benign multiple sclerosis: a distinct clinical intity with therapeutic implications. Curr. Top. Microbiol. Immunol. 2008;318:1-17.

23. Lytovka M.V., Bandurina K.V. Vykorystannia metodu strein-kontrstrein u reabilitatsii khvorykh z miofastsialnym bolovym syndromom poperekovo-kryzhovoho viddilu khrebta [Using of Strain-Sounterstrain method in the physical therapy of patients with myofascial pain syndrome of lumbosacral spine segment]. Pedagogy, psychology and medical and biological problems of physical education and sports. 2011;7:60-63.(in Ukrainian).

24. Arnold D. Evidence for neuroprotection and remyelination using imaging techniques. Neurology. 2007;68(3): 83-140.

25. Lovblad K.0.MRimaging in multiplesclerosis: reviewand recommendations for current practice. Am. J. Neuroradiol. 2010;31:983-989.

26. Simon J.H. Standardized MR imaging protocol for multiple sclerosis: Consortium of MS Centres consensus guide-lines. Am J Neuroradiol. 2006; 27: 455-461.

27. Haensch C. Autonomic disfunction in multiple sclerosi. J. Neurol. 2006; 253(7): 13-19. 
ORCID and contributionship:

Zinovyi M. Ostapyak: 0000-0001-7687-161X A, D, F

Bogdan M. Mytckan: 0000-0002-5853-713x E, F

Przemyslaw Bejga: 0000-0003-4871-4689 A, F

Roman P. Gerich: 0000-0003-4527-4972 B, F

Serg L. Popel': 0000-0001-9019-3966 ${ }^{\text {B, C, F }}$

\section{Conflict of interest:}

The Authors declare no conflict of interest.

\section{CORRESPONDING AUTHOR}

Zinovyi M. Ostapyak

Vasyl Stefanyk Precarpathian National University

57 Shevchenka str., 76025 Ivano-Frankivsk, Ukraine

tel: +380965782295

e-mail:zinoviy6@ukr.net

Received: 21.11.2019

Accepted: 29.06 .2020

A - Work concept and design, B - Data collection and analysis, C - Responsibility for statistical analysis,

D-Writing the article, $\mathbf{E}$-Critical review, $\mathbf{F}$ - Final approval of the article 